\title{
Renal Fossa
}

National Cancer Institute

\section{Source}

National Cancer Institute. Renal Fossa. NCI Thesaurus. Code C142312.

The usual retroperitoneal location of the kidney in the dorsolumbar region of the body. 